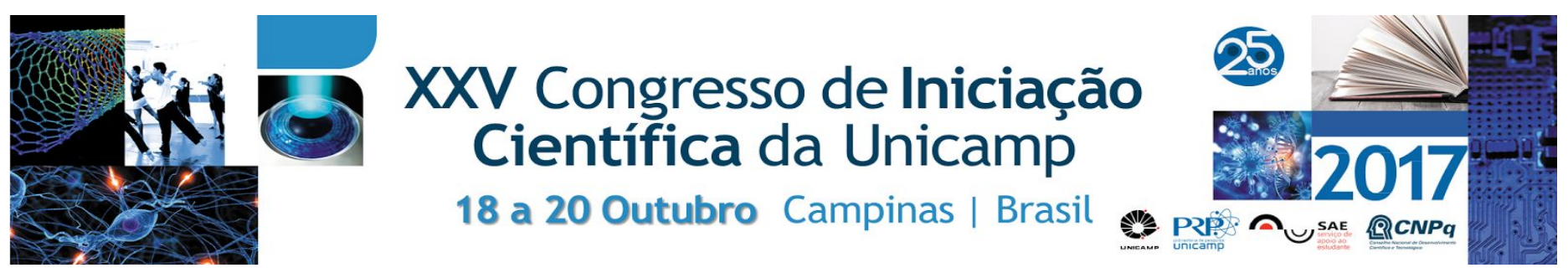

\title{
Análise da deposição dos componentes da matriz elástica em Células Musculares Lisas Vasculares de camundongos deficientes em Fibrilina-1 e MAGP-1.
}

\section{Ana Paula Pires Macêdo*, Cristina P. Vicente, Claudio Chrysostomo Werneck.}

\section{Resumo}

As glicoproteínas das microfibrilas 1, MAGP-1 e a Fibrilina-1, são importantes constituintes da rede de microfibrilas que compõem as fibras elásticas. Uma das principais funções das microfibrilas além de fornecer suporte estrutural para os tecidos é o controle da disponibilidade de fatores de crescimento, em especial da família TGF- $\beta$. Dados do nosso laboratório demonstram que a deficiência de MAGP-1 ou de Fibrilina-1 levam a uma alteração da formação do trombo. Esta alteração desaparece quando os animais são tratados com losartan, anti-hipertensivo que está associado com a diminuição da atividade de TGF- $\beta$. Dados com fibroblastos de derme de camundongos deficientes em Fibrilina-1 sugerem um aumento na deposição de componentes elásticos na matriz extracelular, porém uma análise semelhante deve ser realizada para as células musculares lisas vasculares obtidas a partir destes animais. Sendo assim, o objetivo deste trabalho é isolar e caracterizar células de músculo liso vasculares de camundongos deficientes em MAGP-1 e Fibrilina-1 e analisar o efeito do tratamento com losartan na deposição dos componentes elásticos.

\section{Palavras-chave:}

MAGP-1, Fibrilina-1, células vasculares de músculo liso.

\section{Introdução}

A fibrilina-1, foco deste projeto, tem sua função estrutural como parte das microfibrilas, mas tem também importância na regulação de fatores de crescimento, dentre eles o TGF- $\beta$. Mutações no gene da fibrilina-1 estão relacionadas com a síndrome de Marfan. Modelos da síndrome em camundongos sugerem que nestes animais, há uma maior atividade do TGF- $\beta$, o que leva ao aparecimento de sinais clínicos. Aparentemente, estes sinais podem ser explicados por uma super-ativação do TGF- $\beta$ nesses animais ${ }^{1-3}$. Entre as suas funções primárias, TGF- $\beta$ serve como um estimulador de reparação e regeneração do tecido, como um mediador para a produção de $\mathrm{MEC}$, e no caso da fibrose, como motor de excessiva produção de colágeno ${ }^{4,5}$. Estes sinais têm seu aparecimento diminuído quando tratados com losartan, anti-hipertensivo que atua diminuindo a expressão e ativação de TGF- $\beta^{3}$. Em nosso laboratório, estudamos o efeito da deficiência dos componentes das fibras elásticas na trombogênese. Em camundongos deficientes em MAGP-1 e em Fibrilina-1, é necessário um tempo maior para a formação do trombo. O tratamento de ambos camundongos deficientes com losartan resgata o tempo normal de formação dos trombos, sugerindo uma ação importante desta droga neste processo. Além disto, em cultura de fibroblastos de derme de camundongos deficientes em fibrilina-1 foi possível verificar que o tratamento com losartan aumenta a quantidade dos componentes elásticos na matriz, sugerindo uma menor degradação. Com o objetivo de verificar se isso ocorre nos vasos sanguíneos dos camundongos deficientes em fibrilina-1, pretendemos isolar as células de músculo liso vasculares (VSMC) e submetê-las ao tratamento com losartan. Sendo assim, o objetivo deste projeto é analisar a deposição dos componentes da fibra elástica em VSMC obtidas de camundongos selvagens e deficientes em fibrilina-1 e ainda, expandir nossos estudos para os camundongos deficientes em MAGP-1.

\section{Resultados e Discussão}

As células de músculo liso vasculares foram isoladas utilizando camundongos adultos de 7-8 semanas de idade, obtidos a partir de um cruzamento entre dois camundongos adultos heterozigotos para a mutação no gene da MAGP-1 ou da Fibrilina-1, de acordo com Adhikari e colaboradores, e mantidas em meio de cultura utilizado para crescimento celular DMEM acrescido $10 \%$ Soro Fetal bovino e $1 \%$ penicilina $10.000 \mathrm{U} . \mathrm{I} / \mathrm{ml}$ e estreptomicina $10 \mathrm{mg} / \mathrm{ml}$.

\section{Conclusões}

Até o presente momento, as células de importância para este estudo foram isoladas e os ensaios estão em andamento.

\section{Agradecimentos}

Ao Conselho Nacional de Desenvolvimento Científico e Tecnológico (CNPq), pelo financiamento do projeto e à Fundação de Amparo à Pesquisa do Estado de São Paulo (FAPESP).

\footnotetext{
${ }^{1}$ Neptune, E. R., Frischmeyer, P. A., Arking, D. E., Myers, L., Bunton, T. E., Gayraud, B., Ramirez, F., Sakai, L. Y., and Dietz, H. C. Nat Genet. 2013, 33 , 407-411.

${ }^{2}$ Gao, L. G., Luo, F., Hui, R. T., and Zhou, X. L. Ageing Res Rev. 2010, 9 , 363-368.

${ }^{3}$ Habashi, J. P., Judge, D. P., Holm, T. M., Cohn, R. D., Loeys, B. L., Cooper, T. K., Myers, L., Klein, E. C., Liu, G., Calvi, C., Podowski, M., Neptune, E. R., Halushka, M. K., Bedja, D., Gabrielson, K., Rifkin, D. B., Carta, L., Ramirez, F., Huso, D. L., and Dietz, H. C. Science. 2006, 312, 117-121.

${ }^{4}$ Hinz, B. Matrix Biol. 2015, 47, 54-65.

${ }^{5}$ Pakyari, M., Farrokhi, A., Maharlooei, M. K., and Ghahary, A. Adv Wound Care (New Rochelle). 2013, 2, 215-224.
} 